\title{
Maquiavel, Pandemia e a estrutura político-econômica moderna
}

\author{
Machiavelli, Pandemic and the modern political-economic structure
}

\section{Marcone Costa Cerqueira*}

\begin{abstract}
Resumo: Neste breve artigo, argumentaremos que a pandemia da Covid-19, como outras na história humana, colocou em desnudo as bases da estrutura político-econômica moderna. Defenderemos que tais bases apoiam-se em dois esteios, uma noção política de 'Estado', ápice da organização humana, e uma concepcão racionalista, técnica e produtiva, que promulga a possibilidade de resposta a qualquer crise surgida na sociedade. Como contrapondo a esta estrutura, apresentaremos a teoria maquiaveliana, que aponta para uma relação indelével entre política e fator natural, natureza e sociedade. Nesta teoria, com uma concepção antropológica própria, as necessidades impostas pela natureza frente a ação humanả são determinantes para se pensar a própria construção política. Como resultado, consideraremos ser necessário repensar a estrutura político-econômica moderna em seus pretensos mitos de incontestável avanço político, por meio do 'Estado', e inabalável base racional, principalmente técnico-produtiva, retomando o lugar de importância do fator natural para constituição de uma sociedade mais 'humana'.
\end{abstract}

Palavras-chave: Maquiavel; Pandemia; Covid-19; Fator Natural; Estado; Racionalidade

\begin{abstract}
In this brief article, we will argue that the Covid-19 pandemic, like others in human history, laid bare the foundations of the modern political-economic structure. We will argue that such bases are based on two pillars, a political notion of 'State', the peak of human organization, and a rationalist, technical and productive conception, which promulgates the possibility of responding to any crisis that arises in society. As a counterpoint to this structure, we will present the Machiavellian theory, which points to an indelible relationship between politics and the natural factor, nature and society. In this theory, with its own anthropological conception, the needs imposed by nature in the face of human action are decisive for thinking about the political construction itself. As a result, we will consider it necessary to rethink the modern political-economic structure in its alleged myths of undeniable political advancement, through the 'State', and an unshakable rational basis, mainly technical-productive, returning to the place of importance of the natural factor for the constitution of a more 'human' society.
\end{abstract}

Keywords: Machiavelli; Pandemic; Covid-19; Natural Factor; State; Rationality

\section{Introdução}

A atual discussão em torno de todos os desdobramentos advindos da catastrófica pandemia de Covid-19 que assola o planeta faz suscitar questionamentos nas mais diversas áreas. Desde os mais óbvios, como na área saúde, os sistemas públicos de transporte e demais estruturas básicas, até a própria construção política e sua dependência da estrutura econômica. Pretendemos apresentar uma discussão que busque compreender estes desdobramentos a partir da construção política na relação dos indivíduos e destes para com a natureza. Perpassando não somente uma perspectiva política, engessante, estabelecida a partir de categorias de gestão, organização e instituições públicas, faz-se necessário criticar as estabelecidas bases de uma estrutura político-econômica moderna que, pretensamente, parece gravitar acima dos desafios impostos pela natureza e suas implicações.

Entendemos que na moderna sociedade, a partir de suas estruturas políticoeconômicas, negligencia-se a importância da relação do ser humano com a natureza, bem 
como os resultados potencialmente nefastos para a humanidade, advindos do desequilíbrio nesta relação. Dois fatores compõem as estruturas desta moderna sociedade, o fator político, que está assentado em um conjunto jusnaturalista que estabelece o 'Estado' como salvaguarda do ser humano diante de sua natureza característica, bem como o lança para um estado 'supranatural'; e o fator econômico, que está ancorado em um conjunto racionalista que estabelece o primado da ciência, da tecnologia e da centralidade da lógica produtiva. Para contrapor-se a esta concepção, é preciso buscar uma teoria, ou ainda o pensamento de um autor, que possa basilar uma visão distinta. Uma visão na qual a relação do ser humano para com a natureza, e as necessidades por ela impostas, seja posta como primordial para se postular e compreender a construção política da relação entre os indivíduos. Para esta finalidade, acreditamos poder fiar-nos em alguns aspectos do pensamento de N. Maquiavel.

Maquiavel encontra-se em um hiato entre a tradição clássico-medieval, compreendendo-se aí as construções gregas antigas e cristãs medievais, e a tradição moderna centrada na racionalidade, na noção de 'Estado' e na centralidade da economia. Assumindo esta assertiva, para nosso itinerário, buscaremos compreender primeiro como o florentino estabelece uma concepção antropológica, o que nos proporcionará compreender sua construção de um pensamento político que leva em extrema consideração o fator natural.

Após este passo, nos voltaremos para a compreensão do fenômeno das pandemias na história humana e o surgimento e propagação da pandemia do Covid-19, como ela segue os 'pulsos' de uma sociedade industrial globalizada. Por fim, buscaremos tecer algumas considerações críticas sobre como as bases político-econômico modernas não respondem à premente necessidade de se aliar a construção política humana à sua relação com a natureza.

\section{Maquiavel e a construção política em relação ao fator natural}

Para assentarmos os fundamentos de uma compreensão política em Maquiavel, é preciso clarear os pontos que indicam o que move o agir humano em vista de sua organização política a partir de sua constituição própria e desta para com o fator natural. Não se pretende apenas estabelecer uma simplificação naturalista ou mística do pensamento maquiaveliano a ponto de alocá-lo ainda em uma tradição medieval ou pré-moderna.

Este último é o movimento empreendido por Parel, no qual ele sustenta sua tese de que a filosofia moral e política maquiaveliana estão assentadas em uma visão cosmológica e antropológica da ação política sujeita à determinação de elementos naturais externos ao próprio ser humano, algo totalmente estranho a uma visão 'moderna'. Em suas palavras:

Mas os argumentos em favor de sua nova filosofia moral são derivados de sua cosmologia e antropologia. A última tem lugar somente pelo que ele chama de 'talento natural' (ingegno), imaginação (fantasia), temperamento e os humores. E como qualquer um pode ver, não existe nada de moderno nesta visão de natureza humana. Eu maquiaveliano é muito mais sujeito à influência da qualidade dos tempos, e daí, indiretamente, ao regime dos corpos celestes ${ }^{1}$.

Aceitamos de Parel a perspectiva de que Maquiavel recorre ao uso de termos cosmológicos, os quais destoam de uma tradição cristã-medieval e estão mais próximos de

\footnotetext{
${ }^{1}$ PAREL, The machiavellian cosmos, p. 157.
} 
um paganismo antigo, não corroboramos, porém, a ideia de que a questão da ação política fique condicionada a um misticismo engessante. Sendo assim, nosso movimento é o de compreender a concepção antropológica maquiaveliana (já que ele não estabelece uma antropologia sistemática) como um hiato, uma digressão entre dois fundamentos antropológicos distintos, o primeiro, uma concepção puramente cristã, medieval, na qual o indivíduo humano é pensado enquanto distinto da natureza e, por isso, tendo em sua essência uma natureza espiritual predominante.

O segundo, um fundamento antropológico moderno, constituinte de um jusnaturalismo, no qual há uma natureza humana, não necessariamente espiritual, mas que condiciona e justifica o estabelecimento do 'Estado', e um racionalismo, que estabelece na razão humana um ponto de supremacia e domínio completo do ser humano sobre todo o âmbito natural, principalmente a partir de sua capacidade produtivo-econômica. Em ambos, medieval e moderno, o ser humano está acima do fator natural, dominando-o e moldando-o ao seu interesse.

Entretanto, devemos ainda evitar alocar o acento maquiaveliano em uma herança grega, tal como uma visão aristotélica ou platônica da natureza política do ser humano. Parece-nos pertinente, até determinado ponto, a colocação de Mansfield sobre o papel da necessidade na construção maquiaveliana, a qual indica a inviabilidade de atrelar-se seu pensamento a uma tradição cristã ou grega em relação a natureza humana e principalmente em vista de pré-condicionar a disposição política dos indivíduos. Vejamos a letra do autor:

Para Maquiavel existe apenas um começo - necessidade. [...]. Deus não nos deu um começo perfeito, como diz a bíblia, e a natureza não nos provê com uma potencialidade para a política, como diz Aristóteles. Nós começamos desarmados, desprotegidos, inseguros e completamente amedrontados ${ }^{2}$.

Além de poder corroborar nossa visão de uma concepção antropologia aplicável indutivamente na constituição do viver político, esta perspectiva exposta por Mansfield nos auxilia ainda na tarefa de perceber Maquiavel em posição de contraposição às tradições sustentadas em seu contexto humanista. Todavia, não pretendemos reduzir o pensamento maquiaveliano a um 'naturalismo cosmológico', como Parel, mas também não nos limitaremos a contrapô-lo de forma instrumental aos princípios das tradições grega e medieval. Parece-nos bastante plausível seguir e corroborar a indicação de Mansfield sobre a centralidade da necessidade. Tanto uma necessidade imposta pela relação do ser humano com a natureza, quanto uma necessidade surgida no viver político.

Assim como Mansfield, Vincieri também aponta a questão da necessidade como fator fundamental para se compreender a concepção antropológica maquiaveliana e sua aplicabilidade em sua construção teórica sobre a realidade política, sua mutabilidade e suas regras aplicáveis. Para ele, a questão da necessidade em Maquiavel deve ser alargada para os momentos que precedem o viver civil e lançam o homem na luta contra a natureza. Como segue:

Se trata, pois, de ver se é possível estabelecer uma relação entre esta originária e fundamental insegurança do homem, isto é, entre esta violência que a natureza faz ao homem e a violência que os homens se fazem reciprocamente. Se pode, todavia, dizer em relação a isto, que o que impele os homens a fugir a esterilidade de um país para procurar lugares férteis e a apoderar-se deles com força seja uma necessidade ${ }^{3}$.

${ }^{2}$ MANSFIELD, Machiavelli's virtue, p. 55.

${ }^{3}$ VINCIERI, Natura humana e dominio, p. 16. 
Todavia, o intuito de Vincieri é atrelar esta 'primeira necessidade', a violência da luta humana contra a natureza pela existência, a uma luta interna ao viver civil e a própria necessidade de expansão dos corpos políticos indicada por Maquiavel. Parece-nos que este movimento aproxima demais a construção maquiaveliana de construções jusnaturalistas, tais como a de Hobbes, o que não é, obviamente, nosso objetivo momento.

Em vista disto, corroboramos a visão de Vincieri sobre a questão da necessidade imposta pela luta em vista da sobrevivência na natureza como um dos fatores que impelem o ser humano ao viver político, todavia não abraçamos a ideia de que tal viver político deva ser entendido como o reflexo da 'violência' dessa luta. Na realidade, o que pretendemos destacar é a forma como Maquiavel articula as necessidades advindas da relação dos indivíduos com a natureza e as necessidades surgidas dentro do próprio viver político. Defendemos a tese de que Maquiavel é um autor que coloca em voga a importância de se considerar a relação 'ser humano x natureza' na construção de uma estrutura política.

A primeira indicação para se compreender este aspecto do pensamento maquiaveliano é analisar como ele entende o surgimento da própria sociedade humana, segundo ele: "Nascem as variações de governo entre os homens, porque no princípio do mundo, sendo os habitantes raros, viveram um tempo dispersos como bestas; depois multiplicando sua geração, ajuntaram-se..."4. A partir desta percepção, entende-se que a própria organização política humana se constitui a partir, ou em torno, de um princípio natural, não que justifique a existência de um 'Estado', mas que submete o ser humano a análise das vicissitudes do fator natural. Este fator natural não pode ser negligenciado no momento de se projetar o que seja um florescimento e fortalecimento do corpo político a ser estabelecido. Em vista disto, Maquiavel indica que: "não podendo os homens assegurarem-se senão com a força, é preciso evitar a esterilidade do país, e pôr-se em lugares férteis, onde possa, pela abundância do lugar, ampliar-se e defender-se...”5.

No pensamento político maquiaveliano, o ser humano não é um 'ente' superior, não há uma essência espiritual que torne o homem a 'coroa da criação', nem mesmo uma fuga possível através de um contrato social que livre o ser humano de um pretenso 'estado de natureza'. Como se pode argumentar, há no pensamento de Maquiavel uma constante tensão entre ser humano e natureza, construção política humana e necessidades impostas pelo meio natural. Vejamos ainda sua assertiva mais contundente sobre esta relação inelutável entre ser humano e natureza, posta por Maquiavel ao discutir a maneira como as coisas passadas, históricas, são perdidas e esquecidas, como segue:

... a natureza, como nos corpos simples, quando já se tem ajuntado bastante matéria supérflua, move-se por si mesma, diversas vezes, e faz uma purgação, a qual é a saúde daquele corpo, desta forma intervém no corpo misto das humanas organizações, quando todas as províncias são repletas de habitantes, de modo que não possam viver, nem possam ir a outro lugar, por serem ocupados e repletos todos os lugares, e quando a astúcia e a malignidade humana é vinda em todos os lugares, convém, necessariamente, que o mundo se purgue por um dos três modos [fome, peste ou inundações]: desta forma, os homens, sendo reduzidos a poucos, vivam mais comodamente e tornem-se melhores ${ }^{6}$.

Como posto, esta posição maquiaveliana levou autores como Parel à ver nele uma extremada mistificação da política e em outros como Mansfield, uma distinção em relação à

\footnotetext{
${ }^{4}$ MACHIAVELLI, Discorsi, Opere, I. 2.

${ }^{5}$ MACHIAVELLI, Discorsi, Opere, I. 1.

${ }^{6}$ MACHIAVELLI, Discorsi, Opere, II. 5.
} 
tradição cristã e grega. Postulamos ainda que tal posicionamento maquiaveliano o distingue dos pensadores políticos modernos, principalmente jusnaturalistas, que veem no estabelecimento do 'Estado' (contrato) uma vitória do ser humano sobre seu estado de natureza e sobre as próprias imposições naturais. Mais ainda, o pensamento políticoeconômico moderno se apoiará no domínio da técnica e na lógica produtiva para afastar completamente o fator natural do cálculo de organização política da humanidade.

O pensamento político maquiaveliano estabelece-se sobre a perspectiva de uma compreensão de indelével relação entre a organização política dos indivíduos (corpos compostos) e o fator natural expresso pela necessidade e pelos desafios impostos pela natureza (corpo simples). A organização política, a sociedade humana como um todo, não é uma esfera que possa ser totalmente cindida do campo de influência dos diversos fatores impostos pela natureza.

Partindo destas breves colocações a respeito da relação estabelecida por Maquiavel entre a organização política e a influência do meio natural sobre ela, tendo como base a concepção de que a sociedade humana não está imune as influências de tal relação, passaremos a analisar a forma como as pandemias, especialmente a atual pandemia do Covid-19, põe em xeque a sociedade humana. Como já indicado desde o início, entendemos que a moderna estrutura político-econômica esteia-se em fundamentos políticos, racionais e produtivos, que, presumidamente alocam a sociedade humana em um estágio no qual seu domínio sobre a natureza lhe garante total segurança.

\section{A história humana e as pandemias}

As pandemias não são fenômenos raros para a humanidade, pode-se elencar inúmeros momentos históricos nos quais o ser humano esteve ameaçado. Se analisarmos, por exemplo, a peste que dizimou milhões de vidas durante os séculos XIV e XV, a chamada Peste Negra, ou Peste Bubônica, perceberemos que a propagação da doença seguiu as rotas comerciais da época, principalmente marítimas. De acordo com Shipman ${ }^{7}$, a Peste Negra origina-se no então império Mongol na Ásia e se espalha por toda a Europa por meio do comércio marítimo e, principalmente, pelo forte comércio desenvolvido através da chamada Rota da Seda, que liga a China ao mercado europeu. A grande tensidade populacional, para os padrões da época, existente na Europa do século XIV, especialmente nos centros comerciais da Itália, França, Espanha e Inglaterra, propiciou a rápida disseminação da doença por meio da bactéria causadora, a Yersinia Pestis.

Esta terrível pandemia deixou marcas que seriam sentidas, e refletidas, por vários séculos. O próprio Maquiavel devia ter em mente, ao falar da purgação da natureza pela peste, o terrível acontecimento da Peste Negra em Florença. Como nos aponta Benedictow, a Peste Negra foi descrita pelos grandes poetas florentinos: "Em Florença, o grande poeta renascentista Petrarca tinha certeza de que eles não acreditariam: 'Feliz posteridade, que não experimentará tanta tristeza abismal e considerará nosso testemunho uma fábula”8.

Entretanto, por mais mortífera e cruel que tenha sido a pandemia da Peste Negra, ela levou quase uma década para se espalhar da Ásia por toda a Europa. Os meios de locomoção não permitiam um avanço maior, mesmo seguindo a rota de comércio que sustentava política e economicamente os grandes centros urbanos, a pandemia se movia em uma civilização humana pré-industrial.

\footnotetext{
${ }^{7}$ SHIPMAN, The bright side of the Black Death, p. 410.

${ }^{8}$ BENEDICTOW, The Black Death: The greatest catastrophe ever, p. 5 .
} 
Mas, o que seria então o alcance da pandemia da Peste Negra se já existissem os meios de transportes advindos apenas após a Revolução Industrial? Certamente não temos uma resposta definitiva para essa indagação, porém, podemos analisar outra pandemia que assolou a pujante civilização pós-industrial do início do século XX, a Gripe Espanhola. Surgida sob os escombros deixados pela Primeira Grande Guerra Mundial, a Gripe Espanhola deixou algo entre 17 e 50 milhões de pessoas em todo o globo. Segundo nos informa Goulart ${ }^{9}$, no Rio de Janeiro, apenas em um dia, 22 de outubro de 1918, morreram 930 pessoas, sendo que as mortes um mês antes não chegavam à 50 indivíduos.

Estas cifras nos permitem afirmar que uma pandemia surgida dentro do seio da moderna sociedade industrial tem um potencial de assolar todos os continentes do planeta. Não mais em um contexto restrito de comércio entre um continente e outro, mas dentro de um amplo contexto de globalização no qual a organização política e econômica parece ter alcançado seu ápice produtivo. Deve-se ainda notar que os primeiros casos da Gripe Espanhola na Europa são reportados nos primeiros meses de 1918, como se viu, em outubro do mesmo ano ela matava centenas no continente latino-americano. Esta pandemia foi a primeira surgida em um contexto político-econômico no qual os dois principais fatores de sustentação da moderna sociedade estavam mais fortes, como posto, um domínio da noção política de 'Estado' e uma fé inabalável no poder da racionalidade, por meio da ciência e da tecnologia.

Atualmente, em pleno desenrolar do século XXI, passamos por uma pandemia que desafia todos os recursos constituídos pela sociedade humana, tanto políticos, quanto científicos e tecnológicos. A pandemia causada pelo novo Coronavírus, causador da Covid19, um vírus da mesma classe do vírus causador da Gripe Espanhola, tem colocado em xeque a capacidade de todos os países em gerirem questões que envolvem enormes logísticas públicas. Segundo Belasco/Fonseca ${ }^{10}$, o Coronavírus foi detectado pela primeira vez na China, no final de 2019, primeiro como uma doença desconhecida, depois como um vírus da mesma classe de outros vírus causadores de doenças gripais. Entretanto, a potencialização de sua ação está exatamente no fato de ser uma mutação dentro de uma ampla classe de vírus, as vacinas utilizadas para outros vírus gripais, como a Influenza $\mathrm{A}\left(\mathrm{H}_{1} \mathrm{~N}_{1}\right)$, são ineficazes no caso do Coronavírus.

Todavia, alguns aspectos são compartilhados entre esta nova e terrível pandemia e as pandemias aludidas acima. Tanto no caso da Peste Negra, em menor escala, quando no caso da Gripe Espanhola e da Covid-19, a propagação se deu através das rotas de comércio, principalmente, e de deslocamento entre os indivíduos de diversos países. Outro aspecto compartilhado em todos os casos é a maior proliferação da doença em áreas tensamente povoadas, especialmente os grandes centros urbanos comerciais. Além disso, a atual pandemia da Covid-19 abala os alicerces de uma relação que sempre se mostrou tensa dentro do arranjo social moderno, a saber, a relação entre o poder público, o 'Estado', e o poder econômico, o 'Mercado'.

Diferentemente das outras pandemias, a atual crise causada pela Covid-19 põe em desnudo as crenças que fundamentam as estruturas do arranjo político-econômico por dois motivos, o primeiro, a crítica ao papel do 'Estado' na organização política frente o fator natural, o segundo, o desafio da fé inabalável na racionalidade técnica que sustenta o edifício econômico. Estes dois âmbitos são exponencialmente tensionados em momentos como o atual em que se deve sacrificar a economia em vista da manutenção da proteção dos indivíduos e do ordenamento das instituições públicas. Como já arquitetado em nossa

\footnotetext{
${ }^{9}$ GOULART, Revisiting the Spanish flu: the 1918 influenza pandemic in Rio de Janeiro, p. 105

${ }^{10}$ BELASCO; FONSECA. Coronavirus 2020, p. 02.
} 
introdução, buscaremos desenvolver sucintamente a crítica a esta estrutura políticoeconômica moderna, para, em finalizando, confrontá-la com a posição maquiaveliana.

\section{Os fundamentos da estrutura político-econômica moderna}

Seria demasiadamente oneroso pretender expor neste curto espaço todos os aspectos que fundamentam a estrutura político-econômica moderna, seria necessário articular temas que perpassam a problemática política, passando pela questão da técnica, o fenômeno social das revoluções, até os diversos avanços tecnológicos da indústria. Todavia, pretendemos focar aquelas que acreditamos ser as raízes desta discussão, a saber, a noção de um estágio político no qual o ser humano alcança seu ápice, e a concepção de uma racionalidade que o torna superior e incólume às implicações do fator natural.

A noção de estágio político à qual nos referimos é exatamente aquela que apresenta a organização política, o 'Estado', como refúgio no qual o ser humano se protege de seu 'estado de natureza', alcança seu ápice e promulga as bases de uma sociedade que pode prover a libertação dos ditames do fator natural. Dois pontos são necessários para se compreender tal noção, primeiro, a ideia de que é possível abandonar uma pretensa natureza humana definidora, ou pelo dominá-la, a qual subsistirá apenas como lembrança da necessidade de se estabelecer um 'contrato' entre os indivíduos. O segundo ponto, a esperança de que neste novo estágio todas as crises derivadas das relações sociais entre os indivíduos possam ser geridas, principalmente aquelas crises que colocam em risco o equilíbrio político.

Certamente que a noção política à qual nos referimos encontra expressão no jusnaturalismo, principalmente a partir de Hobbes, o qual, como aponta Greenleaf, tinha a intenção deliberada de "apresentar uma teoria política e ética firmemente baseada nos princípios da natureza cientificamente concebida e deste modo (ele supunha)

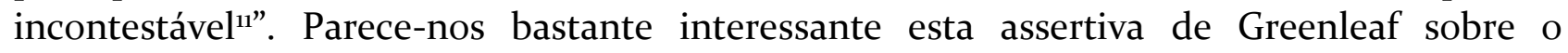
pensamento hobbesiano, pois, apresenta a perspectiva que sustenta o edifício jusnaturalista e as bases da moderna estrutura política. A noção de uma compreensão 'científica' da natureza, principalmente humana, que possibilita ao homem a construção de um estágio político e ético que representa o ápice de sua história social.

Mais que um simples estágio avançado da história humana, o 'Estado', ou a teoria política que o fundamenta, ergue-se como 'incontestavelmente' superior e insuperável. A questão aqui está exatamente em se erigir uma ilusão que fundamenta uma irreal independência humana conquistada a partir de sua organização política. $O$ fato de se postular que o ser humano é capaz de abandonar sua natureza definidora e construir uma organização social que possa gerir toda e qualquer crise derivada das relações entre os indivíduos, bem como a relação da própria sociedade com o fator natural, levou a um mito da inexpugnabilidade da política moderna.

Este mito tem crescido exponencialmente a partir do fortalecimento cada vez mais estrutural das instituições públicas, as quais, estabelecidas sobre as bases de uma política pretensamente científica, ignora os aspectos transitórios e mutáveis das relações sociais humanas, bem como do próprio fator natural. O resultado disto são ações políticas advindas das instituições públicas, detentoras do poder, que engessam demasiadamente as respostas necessárias às crises humanitárias que envolvem todos os agentes sociais, principalmente os menos favorecidos. Vê-se esvanecida a falsa esperança de que o modelo político moderno, ilusoriamente estabelecido na superioridade da noção de 'Estado', possa gerir toda e

${ }^{11}$ GREENLEAF, Hobbes: o problema da interpretação, p. 58 
qualquer crise surgida na sociedade. Faze-se necessário admitir que o ser humano não está incólume às implicações do fator natural, seja ele qual for, desastres naturais, doenças, fome, etc, muito menos está protegido de seu semelhante que o explora e dilacera.

Como indicado, este é, sucintamente, o primeiro ponto de apoio da estrutura político-econômica moderna, o segundo, como posto, é uma noção de racionalidade expressa, principalmente, em termos técnicos e produtivos. O primeiro mito, aquele da possibilidade de um estágio político que se configure como ápice da organização social humana, traz consigo o segundo mito, o qual apresenta a possibilidade de harmonização das relações sociais, e segurança, principalmente por meio da capacidade de responder às necessidades de todos os agentes sociais.

Marcuse é bem enfático ao apontar esta questão, como segue:

O progresso técnico, estendido a todo um sistema de dominação e coordenação, cria formas de vida (e de poder) que parecem reconciliar as forças que se opõem ao sistema e derrotar ou refutar todos os protestos em nome das perspectivas históricas de liberdade da labuta e da dominação ${ }^{12}$.

Esta perspectiva exposta por Marcuse ilustra bem as bases da estrutura políticoeconômica às quais estamos buscando criticar. A partir de uma racionalidade que estabelece o primado da técnica, sendo o resultado da centralidade do poder da razão humana, postula-se as bases de uma sociedade que pode resolver as oposições, promover a harmonização entre os indivíduos e a satisfação de todas as suas necessidades. $\mathrm{O}$ apoio econômico desta estrutura se sustenta exatamente pela ideia de que apenas através da racionalidade técnica é possível dominar o fator natural, fortalecer a organização política, estabilizá-la, e construir uma sociedade preparada para gerir qualquer crise, política ou natural.

Os principais arautos destes mitos são aqueles que se beneficiam mais da ilusão de uma estrutura político-econômica que se sustenta sozinha, ou seja, que se arroga autossuficiente e promulgadora de uma pujança que cobre a todos indiscriminadamente. Seja no campo político ou no econômico, a ideia de uma estabilidade inabalável, proporcionada por um modelo político incontestável e uma racionalidade técnica avançada, mascara a necessidade de se levar em conta os aspectos transitórios, mutáveis, na maioria das vezes imprevisíveis, que podem surgir tanto do fator social quanto do fator natural. $\mathrm{O}$ primeiro decorrente das relações entre os indivíduos, o segundo surgido na inelutável relação do ser humano com a natureza.

\section{Considerações finais}

Diante do que expusemos nestas breves páginas, qual seria a conclusão à se tirar diante da assoladora realidade da pandemia causada pela Covid-19? Parece-nos que a principal conclusão, dentre as inúmeras possíveis, é a necessidade de se repensar, criticamente, os mitos que sustentam a estrutura político-econômica moderna, os quais ilusoriamente promulgam a possibilidade de existência de uma sociedade que é imune às implicações de crises causadas pelo fator natural, tal como a pandemia de Covid-19, bem como as crises surgidas das relações sociais. Ao trazermos Maquiavel para esta discussão, destacamos sua percepção de que o ser humano, mesmo dentro de sua organização política e social, é ainda um ser indelevelmente sujeito às inconstâncias do fator natural.

${ }^{12}$ MARCUSE, One-dimensional man, p. xii, introduction. 
Tal percepção nos leva a rever as construções política e econômica modernas que postulam uma irrevogável evolução humana, a qual permite a construção de sociedade que se ancora em uma estrutura estatal forte e uma incontestável capacidade produtiva. $\mathrm{O}$ que se vê atualmente são governos, 'Estados', completamente despreparados para lidar com a crise causada pelo fator natural da pandemia, estruturas políticas frágeis que não garantem a isonomia social ou mesmo o acesso de todos ao atendimento adequado. Além disso, vê-se também a tão poderosa máquina econômica de joelhos, agonizando em um modelo produtivo pretensamente inabalável em suas bases técnicas.

Talvez Maquiavel tenha razão em afirmar que a natureza 'se purga da raça humana', principalmente naqueles lugares onde as 'províncias estão repletas de habitantes', ou seja, os grandes centros populacionais, como foi também no caso da Peste Negra e da Gripe Espanhola. Mesmo que tenhamos agora muito mais recursos para compreendermos de onde vem a ameaça, vemos que somos frágeis, tanto como 'espécie' quanto como sociedade política. É preciso descer do pedestal erigido na modernidade e nos curvamos, respeitosamente, diante da natureza e 'consultá-la' mais assiduamente durante a promulgação de nossos modelos políticos e econômicos. Mais que isso, assim como Maquiavel, é necessário reconhecer que o cálculo de construção política não pode ser resolvido em uma única equação. $\mathrm{O}$ mito de que a construção de um modelo político inabalável é possível deve ser abandonado, contestar o 'incontestável' dos teóricos da política e dos técnicos do racionalismo produtivo.

Infelizmente haverá ainda novos desafios na história humana, certamente outras pandemias assolaram nossas sociedades, a questão é saber se um novo modelo de estrutura político-econômica também surgirá, menos ilusório e mais aberto a lidar com os fatores imprevisíveis, tanto das relações sociais quanto da relação entre ser humano e natureza.

\section{Referências}

BELASCO, Angélica Gonçalves Silva; FONSECA, Cassiane Dezoti da. Coronavírus 2020. Revista Brasileira de Enfermagem. 2020;73(2):e2020n2.

BENEDICTOW, Ole J. The Black Death: The greatest catastrophe ever. History Today, London Volume 55, Issue 3, March 2005, pp. 3 - 9.

GOULART, A. da C.: Revisiting the Spanish flu: the 1918 influenza pandemic in Rio de Janeiro. História, Ciências, Saúde - Manguinhos, v. 12, n. 1, Jan.-Apr. 2005, pp. 101-42.

GREENLEAF, William Howard. Hobbes: o problema da interpretação. In: QUIRINO, Célia Galvão; SOUZA, Maria Teresa Sadek R.. (Orgs.) O pensamento político clássico: Maquiavel, Hobbes, Locke, Montesquieu, Rousseau. São Paulo: T. A. Queiroz Editor, 1992.

MACHIAVELLI, Niccolo._Opere. A cura di Mario Bonfanini. Milano/Napoli: Riccardo Ricciardi Editore, 1954.

MANSFIELD, Harvey Claflin. Machiavelli's virtue. Chicago: The University of Chicago Press, 1998.

MARCUSE, Herbert. One-dimensional man: studies in the ideology of advanced industrial society. Boston: Beacon Press, 1972.

PAREL, Anthony. The machiavellian cosmos. New Haven/London: Yale University Press, 1992. 
10 | Maquiavel, Pandemia e a estrutura político-econômica moderna

SHIPMAN, Pet Lee. The bright side of the Black Death. American Scientist. Volume 102, Number 6, November - December, 2014, pp. 410.

VINCIERI, Paolo. Natura humana e dominio: Machiavelli, Hobbes, Spinoza. Ravenna: Longo Editore, 1984. 